\title{
Contramodelos cavaleirescos na literatura genealógica e cronística medieval ibérica - diálogos com a ética aristotélica
}

\author{
José D’Assumpção Barros*
}

\begin{abstract}
RESUMO
Neste artigo, preocupado em examinar a intertextualidade da literatura medieval com o pensamento aristotélico, são examinadas algumas narrativas medievais da Idade Média portuguesa que aparecem nos livros de linhagens do século XIII, com vistas à identificação dos principais traços de um Imaginário Cavaleiresco, que foi essencial para a formação da identidade nobiliárquica do mesmo período. Investiga-se, assim, a influência da ética aristotélica no padrão cavaleiresco que é definido preponderantemente nas narrativas linhagísticas.

Palavras-chave: Ética aristotélica. Narrativas medievais. Idade Média Ibérica.
\end{abstract}

\section{Considerações iniciais}

É bastante conhecido o diálogo de textos medievais de origens diversas com as obras de Aristóteles. O campo da Escolástica, naturalmente, nos oferece as referências mais óbvias e notórias. Contudo, fontes as menos previsíveis, como as crônicas e outras fontes narrativas do período, podem também nos mostrar, em menor ou maior intensidade, a intertextualidade aristotélica. O presente artigo pretende investigar a relação entre a intertextualidade medieval-aristotélica e certas fontes narrativas que fazem parte da literatura cronística e que giram em torno da temática do Ideal Cavaleiresco, tão caro à nobreza medieval. Nossas fontes centrais serão os livros de linhagens - genealogias que, na Idade Média portuguesa, entremeavam listas de antepassados nobiliárquicos com narrativas de diversos teores sobre os mesmos. São essas narrativas que nos interessarão mais especificamente, no sentido de que frequentemente transparece, através dos exemplares que elas encaminham, todo um modelo ético que pode ser sistematicamente examinado.

* Universidade Federal do Rio de Janeiro - UFRJ. 


\section{Influência de Aristóteles na Idade Média}

Aristóteles teve uma enorme influência na Idade Média. ${ }^{1}$ À parte as obras de Lógica e Retórica, as quais haviam sido conservadas por linha mais direta da herança greco-romana, uma grande parte dos textos aristotélicos direcionados a uma grande gama de assuntos somente chega até os homens medievais de cultura a partir dos árabes. ${ }^{2}$ Os comentários de Averróis (1126-1198), filósofo islâmico nascido em Córdova, são imprescindíveis nesta direção. ${ }^{3}$ De Averróis, a influência de Aristóteles chegaria a nomes como os de John de Salisbury (1115-1180), Alberto Magno (1193-1280 d. C.), Roger Bacon (1214-1294 d. C.), Santo Tomás de Aquino (1225-1274 d. C.), Siger de Brabant (1235-1284 d. C.) e Marsílio de Pádua (1275-1342 d. C.). ${ }^{4}$ A presença de tantos nomes da segunda metade do século XII e do século XIII entre os que recebem a obra aristotélica através dos árabes não é casual. A Universidade de Paris, a mais notória das grandes universidades medievais, destaca-se em especial neste século, e é lá que podem ser notadas, pela primeira vez, as traduções aristotélicas e os textos dos comentadores árabes. ${ }^{5}$ Trata-se de um ambiente efervescente, que logo inspiraria os meios universitários e eruditos de outros países da Europa.

A obra máxima de Averróis, para além de sua enorme importância na própria cultura islâmica, contribuirá diretamente para transmitir o aristotelismo aos cristãos medievais. Referimo-nos aos Comentários ao corpus aristotelicum. Este grande conjunto compreende três grandes divisões: os comentários menores (Yawami), médios (Taljisat) e menores (Tafasir). Desses, é importante desde já ressaltarmos a importância dos "Comentários médios" para a temática de que tratamos - a qual abordará a influência, nos livros de linhagens, da Ética a Nicômaco - isto porque é precisamente nesta divisão que se acham, mais propriamente, os comentários à Ética de Nicômaco, entre outros voltados para outras obras aristotélicas. O comentário médio sobre a Ética de Nicômaco de Aristóteles teria sido elaborado por Averróis em $1171 .^{6}$

1 Para uma análise de maior profundidade sobre a trajetória e obra de Aristóteles, ver HÖFFE, Otfried. Aristóteles. Porto Alegre: Artmed, 2008.

2 BONI, Luis A. de. Apresentação. In: São Tomás de Aquino. Suma teológica. Porto Alegre: UFRS, 1980. p. I-XII.

3 Para um estudo sobre a trajetória intelectual de Averrois, ver URVOY. Dominique. Averroès: Les ambitions d'un intellectuel musulman. Paris: Flammarion, 1998.

4 CHEVALIER, Jacques. Histoire de la pensée. II, Paris, Racine, 1956, p. 272.

5 GILSON, Etienne. A filosofia na Idade Média. São Paulo, Martins Fontes, 1998, p. 477.

6 MATOS, Manuel Cadafaz de. Contributo para o estudo da recepção dos textos de Averróis (11261198) na península ibérica entre os séculos XIII e XV numa perspectiva da História do Livro. Humanitas, 1998, v. L, p. 444. 
Entre os ibéricos, aspecto que será importante para o nosso tema em estudo, houve igualmente uma recepção significativa das obras de Averróis (e, consequentemente, do extrato aristotélico que foi trazido por elas), tal como podemos ver de maneira mais sistemática em um estudo de Manuel Cadafaz de Matos (1998). Tal se verifica sobretudo nos séculos XIII e XIV, o que coincide com o nosso período em estudo e, desse modo, agrega-se como mais um indício sobre a penetração das intertextualidades aristotélicas na época dos chamados livros de linhagens.

\section{A referência a Aristóteles no prólogo do livro de linhagens}

Começaremos por fazer notar que existe um modelo de ideal cavaleiresco, e consequentemente um contramodelo anticavaleiresco correspondente, que acaba por tomar forma de maneira bastante enfática em diversas narrativas contidas nos três grandes livros de linhagens que conhecemos do reino de Portugal nos séculos XIII e XIV. O nosso objetivo inicial será examinar esses modelos e contramodelos, verificando também como se dá mais concretamente a intertextualidade do Livro de linhagens do Conde Dom Pedro, o mais famoso dos nobiliários medievais portugueses, com a ética aristotélica, citada no prólogo do mesmo livro.

Em pesquisa anterior ${ }^{7}$, os resultados a que chegamos a partir do rastreamento dos modelos e contramodelos presentes nas narrativas linhagísticas e da utilização de quadrados semióticos para a compreensão de seus significados, vieram a mostrar que, por de trás do código cavaleiresco proposto pelos livros de linhagens portugueses, há um sistema ético envolvido. A busca da identificação de uma dimensão aristotélica presente nesse sistema ético será o que nos interessará neste momento. Por hipótese, partiremos de algumas constatações preliminares. Existe no sistema ético que parece emergir das narrativas cavaleirescas dos livros de linhagens algo que se coloca como "justo" na sua relação com o "não-justo" e com o "injusto", e elementos que medeiam esta relação (a qualidade do ato como "voluntário" e "consciente", a necessidade de retribuir a justiça ou a injustiça com um ato que instaure ou restabeleça a "reciprocidade", a "hierarquização" de tipo geométrico entre "males menores" e "mal maior", e assim por diante). Esses elementos coincidem com a "ética aristotélica", e é extremamente significativo o fato de Aristóteles ser o único autor que aparece nominalmente citado no prólogo do Livro de linhagens do Conde Dom Pedro. Naquela oportunidade, registrada 
logo ao princípio do "Prólogo", o Conde apropria-se à sua maneira de um certo dito de Aristóteles: Esto diz Aristotiles: que se homees houvessem antre si amizade verdadeira, nom haveriam mester reis nem justiças. (Livro de linhagens do Conde Dom Pedro, 1980).

Existe uma boa possibilidade de que o trecho a que se refere o Conde D. Pedro nestas páginas iniciais de seu nobiliário seja uma passagem da própria Ética a Nicômaco, na qual o filósofo grego diz que "quando os homens são amigos não necessitam de justiça” (ARISTÓTELES, 1973, p. 379). No mesmo parágrafo, aliás, Aristóteles acrescenta ainda que "considera-se que a mais genuína forma de justiça é uma espécie de amizade” (ARISTÓTELES, 1973, p. 379), o que parece produzir ressonâncias na expressão "amizade verdadeira" utilizada pelo Conde na passagem acima. De resto, o próprio Livro VIII da Ética a Nicômaco refere-se, na sua totalidade, à questão da "amizade", abordando em especial as suas relações com a justiça e as formas políticas. Tudo isto leva-nos a crer que é a própria Ética a Nicômaco que está na base do comentário do Conde, e que portanto teria sido uma obra conhecida do compilador do Livro de linhagens do Conde Dom Pedro a ponto de influenciá-lo seja na seleção das narrativas, seja na construção de um discurso que parece pontuar determinados aspectos da ética aristotélica. Veremos que esta suspeita parece se confirmar com a confrontação dos próprios casos linhagísticos com certas passagens da obra do filósofo grego. ${ }^{8}$

\section{O modelo ético da Ética a Nicômaco}

De fato, o circuito de narrativas que tivemos oportunidade de examinar parece estar mergulhado significativamente em um sistema ético nos moldes aristotélicos - onde a questão da necessidade de o "ato justo" ser acompanhado de "vontade" concretiza, nos exempla linhagísticos, o que em teoria se acha registrado na Ética a Nicômaco:

Sendo os atos justos e injustos tais como os descrevemos, um homem age de maneira justa ou injusta sempre que pratica tais atos voluntariamente. Quando os pratica involuntariamente, seus atos não são justos nem injustos, salvo por acidente, isto é, porque ele fez coisas que redundam em justiças ou injustiças. É o caráter voluntário ou involuntário do ato que determina se ele é justo ou injusto, pois, quando é voluntário, é censurado, e pela mesma razão se torna um ato de injustiça; de forma que existem coisas que são

8 Para estudos mais específicos sobre a Ética Aristotélica, ver GAUTHIER, René-Antoine. La morale d'Aristote. Paris: Presses Universitaires de France, 1958 e NODARI, Paulo Cesar. A Ética Aristotélica. Síntese Nova Fase. Belo Horizonte, UFMG, vol.24, n. 79, 1997, p. 383-410. 
injustas, sem que no entanto sejam atos de injustiça, se não estiver presente também a voluntariedade. (ARISTÓTELES, 1973, p. 332 - destaques meus).

Antes de mais nada, podemos perceber que o filósofo grego reconhece a existência de atos que "não são justos nem injustos" - e que, portanto, seriam antes classificáveis como atos "não justos" ou "não injustos", prenunciando aqui um quadrado semiótico perfeitamente elaborado. Por outro lado, após estabelecer uma relação necessária entre a classificação do ato como justo ou injusto e a sua "voluntariedade", Aristóteles deixa claro a seguir que entende por voluntariedade a "consciência" do ato e o fato de que ele não seja praticado por coação ou imposição:

Por voluntário entendo, como já disse antes, tudo aquilo que um homem tem o poder de fazer e que faz com conhecimento de causa, isto é, sem ignorar nem a pessoa atingida pelo ato, nem o instrumento usado, nem o fim que há de alcançar (por exemplo, em quem bate, com o que e com que fim); além disso, cada um desses atos não deve ser acidental nem forçado (se, por exemplo, A toma a mão de $\mathrm{B}$ e com ela bate em C, B não agiu voluntariamente, pois o ato não dependia dele). (ARISTÓTELES, 1973, p. 332).

\section{A presença do modelo nas narrativas dos livros de linhagens}

Alguns dos exempla presentes nas narrativas dos livros de linhagens adequamse perfeitamente à ética acima exposta. O personagem Pedro Alvelo da narrativa "O Tenreiro" (LL 36E9), por exemplo, era um nobre honrado que havia sido enganado pelo primo e que, embora sabendo "em quem e com que batia", não sabia "com que fim" (ou imaginava que o seu ato se sustentava em uma resposta a um desafio, na verdade inexistente). Em suma, nesse enredo narrativo, o bom nobre é induzido maldosamente por um outro a cometer um crime, acreditando que, na verdade, estava defendendo a sua honra. Por isto, na sequência, ele é liberado pelo rei de qualquer acusação de ter praticado um ato injusto.

Já na narrativa sobre "O alcaide de Celorico" (LL55Q6), temos o caso de um nobre que se tornou um verdadeiro modelo de comportamento dentro do âmbito cavaleiresco, esforçando-se obstinadamente o protagonista nobre por resolver, dentro dos ditames habitualmente aceitos pelo ideal cavaleiresco, as pendências intervassálicas das quais precisava se livrar. Nesse caso o nobre, que busca a todo o custo liberar-se corretamente de um vínculo de vassalidade com relação a um suserano que se esquiva de encontrá-lo, não havia cometido rigorosamente um ato injusto ("não agiu voluntariamente, pois o ato não dependia dele"). 
A narrativa sobre "Fernão Rodrigues" (LL 11C7) - trazendo à tona o caso de um nobre honrado que é levado a crer que estava sendo traído pela mulher e que, por isso, a assassina brutalmente, embora ela, na verdade, fosse inocente mostra bem o caso do infrator involuntário que, acreditando agir de acordo com o princípio da "reciprocidade", ignora, na verdade, "a pessoa atingida pelo ato". ${ }^{9}$ As manipulações que envolvem Pedro Alvelo e Fernão Rodrigues, aliás, enquadramse perfeitamente no que Aristóteles classifica, logo a seguir, como "enganos": "Os que são infligidos por ignorância são enganos quando a pessoa atingida pelo ato, o instrumento ou o fim a ser alcançado são diferentes do que o agente supõe". (ARISTÓTELES, 1973, p. 332).

Também a narrativa "O rapto da Ribeirinha" (LL 36BN9) nos mostra um caso bastante elucidativo. Uma Dama da alta nobreza portuguesa é raptada e forçada a viver maritalmente com o seu raptor, que a leva para um país estrangeiro, de modo a escapar de possíveis vinganças da família da vítima. A personagem, então, manipula o seu raptor, convencendo-o a comparecer perante o rei de Portugal para regular a sua situação conjugal. Tratava-se, contudo, de mero artifício, pois no momento em que estão diante da mediação régia, a personagem acusa o seu raptor e faz com que ele seja condenado. Aqui, portanto, a personagem, que é obrigada a escolher entre o "mal menor" (a mentira e o fingimento de sujeição ao seu raptor) e o "mal maior" (a desonra não reparada), acha-se adequada a um outro passo da Ética a Nicômaco,

pois o menor mal é considerado um bem em comparação com o mal maior, visto que o primeiro é escolhido de preferência ao segundo, e o que é digno de escolha é bom, e de duas coisas a mais digna de escolha é um bem maior. (ARISTÓTELES, 1973, p. 325-326).

Ou, de maneira ainda mais clara, registra-se no Livro III a seguinte passagem: "Por ações desta espécie os homens são até louvados algumas vezes, quando suportam alguma coisa vil ou dolorosa em troca de grandes e nobres objetivos alcançados." (ARISTÓTELES, 1973, p. 281).

9 "Fernão Rodrigues" é um nobre que, imaginando-se vítima de um adultério, assassina sua esposa inocente em função de um mal entendido perpetrado pelas circunstâncias e agravado por uma personagem maldosa (LL 11C7). Tornado consciente da injustiça de seu crime, o nobre chega a entregar a própria vida ao sogro, que é nada mais, nada menos, que o imperador da Espanha. A passagem da não-justiça (-S1) à injustiça (S2) deve ser associada à tomada de consciência de que a esposa era inocente, e a correção da injustiça (-S2) à proposta do nobre de que o pai da vítima disponha de sua própria vida. A "justiça plena" (S1) corresponde à decisão magnânima do imperador, que decide não puni-lo em vista de compreender que o infrator teria agido cavalheirescamente, tanto para o mal como para o bem (já que não tinha consciência de que a esposa, efetivamente, não praticara adultério). 
É bem verdade que o filósofo grego faz distinções entre os vários casos de escolha entre o "mal menor" e o "mal maior", devendo alguns serem merecedores de louvor e outros de perdão:

\begin{abstract}
Algumas ações, em verdade, não merecem louvor, mas perdão, quando alguém faz o que não deve sem sofrer uma pressão superior às forças humanas e que homem algum poderia suportar. (ARISTÓTELES, 1973, p. 281).
\end{abstract}

Essas nuances também estão presentes no material linhagístico de valoração cavaleiresca. A dama que se submete ao raptor para realizar o seu projeto de vingança em "O rapto da Ribeirinha" (LL 36BN9) tende mais a ser perdoada do que louvada, e o nobre que luta desesperadamente para sanar uma infração cavaleiresca que não dependeu dele tende a ser louvado e a se transformar, até mesmo, em um paradigma vassálico em "O alcaide de Celorico". (LL 55Q6).

\title{
O constrangimento da passagem do cavaleiresco ao não-cavaleiresco
}

As correlações entre o código cavaleiresco proposto e a ética aristotélica não param por aí. A vingança da honra, que ocupa um papel tão importante no circuito de relatos presentes no nobiliário, adequa-se, por exemplo, ao princípio da "reciprocidade" proposto noutro passo da Ética a Nicômaco (ARISTÓTELES, 1973, p. 328). Mas existe ainda um outro ponto que denuncia, de forma ainda mais enfática, a apropriação linhagística da ética aristotélica. Referimo-nos ao fato de que não se mostra possível para um "bom nobre" passar do cavaleiresco ao nãocavaleiresco sem um "constrangimento". Se ele ignora, em um primeiro momento, esta passagem, o constrangimento ou a necessidade de remissão não surge senão quando ele toma conhecimento do ato. É o caso, por exemplo, do nobre enganado em "O Tenreiro" (LL 36E9) ou da narrativa sobre Fernão Rodrigues, fidalgo que mata involuntariamente a própria esposa em "O assassinato de Dona Estevainha". (LL 11C7). Essa tomada de consciência acompanhada da dor ou do arrependimento está na base de uma distinção que Aristóteles faz entre o "não-voluntário" e o "involuntário":

Tudo o que se faz por ignorância é não-voluntário, e só o que produz dor e arrependimento é involuntário. Com efeito, o homem que fez alguma coisa devido à ignorância e não se aflige em absoluto com o seu ato não agiu voluntariamente, visto que não sabia o que fazia; mas tampouco agiu involuntariamente, já que isso não lhe causa dor alguma. (ARISTÓTELES, 1973, p. 282). 
Distingue-se, portanto, o ato injusto "voluntário" - que é próprio do "homem mau", a não ser no já mencionado caso da escolha de um "mal menor" em detrimento do "mal maior" - dos atos injustos que são "não-voluntários" ou "involuntários", sendo que este último implica, necessariamente, uma tomada de consciência em algum momento, e consequentemente no contraponto do "constrangimento". No caso dos relatos linhagísticos, esse constrangimento costuma expressar-se em "vergonha", "arrependimento", ou pelo menos em uma imperiosa necessidade de "remissão" e de recuperação da imagem cavaleiresca idealizada perante os pares. Dessa forma, a passagem do "não-voluntário" ao "involuntário", ou do plano da inconsciência ao plano da consciência, vem acompanhada, obrigatoriamente, de um "constrangimento" sempre que o agente for essencialmente "bom". Aristóteles é bem explícito com relação a esta questão: "Além disso, a prática de um ato considerado involuntário em virtude de uma ignorância desta espécie deve causar dor e trazer arrependimento." (ARISTÓTELES, 1973, p. 283).

\section{Um mostruário de situações éticas}

Um grande número de aspectos incluídos na Ética a Nicômaco, conforme se depreende dos exemplos expostos, parece encontrar uma ressonância efetiva no material linhagístico que serve de exemplum para a correta inserção do "bom nobre" dentro do âmbito cavaleiresco. As distinções entre o "justo", o "nãojusto" e o "injusto"; entre o "voluntário", o "não-voluntário" e o "involuntário"; a identificação do "constrangimento" (dor ou arrependimento) que decorre do fato de um "homem justo" tomar consciência de ter praticado um ato injusto; a legitimidade de escolher o "mal menor" para evitar o "mal maior"; a "reciprocidade" em que se fundamenta a reparação do mal ou da justiça infligida, no caso cavaleiresco implicando a vingança justificada ou a reparação da honra, e, por fim, a "virtude" encarada como um meio termo entre um excesso e uma carência, são os elementos de uma ética aristotélica que parecem informar, em alguns de seus níveis, o código cavaleiresco proposto pelo autor do Livro de linhagens do Conde Dom Pedro.

É assim que, nessa perspectiva, o nobiliário apresenta-se como um mostruário de situações práticas e concretas, prontas a oferecer ao cavaleiro-leitor um repertório de possibilidades éticas. Dito de outra forma, o nobiliário incorpora uma dimensão didática que pretende orientar o cavaleiro no seu agir em relação aos seus semelhantes. Um último elemento desta ética a ser considerado consiste na noção de que, se a felicidade de uma vida cavaleiresca e virtuosa é um fim em si mesmo a ser atingido, essa felicidade cavaleiresca é uma "atividade" que só pode 
ser assegurada mediante o esforço. E mais uma vez encontramos uma ideia da ética aristotélica profundamente entranhada nos exemplos narrativos do nobiliário do Conde D. Pedro: a de que "a vida virtuosa exige esforço" (ARISTÓTELES, 1973, p. 428). Nessa passagem encontra-se tanto a definição da "felicidade" como uma "atividade", como a noção de que "a vida feliz é virtuosa" e exige esforço.

De fato, uma vez carregado para o âmbito não-cavaleiresco que ameaça o estatuto da virtude cavaleiresca e a felicidade verdadeira, o cavaleiro deve lutar arduamente para recobrar o equilíbrio original. Tenha sido deslocado do âmbito cavaleiresco por uma fatalidade (LL 11C7), por razões involuntárias (LL 95Q6), pela má fé ou manipulação de um outro (LL 36E9), pela violência do rapto (LL 36BN9) ou da captura (LL 65A1), somente o esforço consciente poderá trazer o bom nobre de volta ao seu âmbito natural. Os que fracassam na realização desse esforço ficam aprisionados definitivamente no âmbito não-cavaleiresco e perdem a "boa nobreza", se um dia a tiveram (LL 41I5) 10. O "esforço" completa, portanto, o conjunto de noções constitutivas de uma ética que se encontra implícita no nobiliário examinado.

Denunciada pelo pormenor registrado logo ao início do "Prólogo" do Livro de linhagens do Conde Dom Pedro, uma leitura de Aristóteles parece estar, dessa forma, presente nos fundamentos éticos das narrativas linhagísticas e ser confirmada pelos próprios conteúdos e noções envolvidos nos seus relatos sobre transgressão e reparação cavaleiresca. De um modo ou de outro, a intencionalidade de dar uma coerência ao código cavaleiresco através das narrativas linhagísticas mostra-se compatível com a ética aristotélica. Prossigamos, portanto, no rastreamento de situações de transgressão e valoração cavaleiresca apreensíveis em nossas fontes. Já registrados os casos que se referem aos "bons nobres", cabe agora investigar a figura do "mau nobre", este que pratica o ato injusto voluntariamente e com consciência da sua injustiça.

\section{Os traidores}

Encontram-se registradas diversas narrativas sobre traidores ou infratores cavaleirescos nos livros de linhagens. Não raro, essas narrativas aparecem associadas a objetivos conscientes de depreciar determinado indivíduo ou linhagem. Mas um de seus mais significativos papéis é reforçar, por contraposição, e de diversas maneiras, os valores cavaleirescos, o que pode atender tanto à nobreza

10 Respectivamente as já mencionadas narrativas "Fernão Rodrigues de Castro", "O alcaide de Celorico", "O Tenreiro", "O rapto da Ribeirinha", "Pero Novais", "Gonçalo Pires Ribeiro". 
como ao projeto centralizador régio. As famosas traições de "Raimundo Viegas de Portocarreiro" e de "Mem Cravo" constituem dois dos mais significativos exemplos (LL 43F5 e LL 47C4). Ambas referem-se ao rompimento injustificado de vínculos vassálicos. A infração à ética cavaleiresca propriamente dita, mais do que a infração aos valores feudo-vassálicos, também se aproxima desse tipo de narrativas. É o caso da sequência sobre a covardia de Mem Soares na narrativa sobre "Echega Guiçoi de Souza" (LL 22A5), que cegou seis condes enquanto dormiam e termina justiçado. A mesma narrativa é referida em registro de intertextualidade pela narrativa sobre "Gonçalo de Souza" (LL 22A5), que contrapõe descendentes das personagens envolvidas na primeira narrativa.

Em um extrato ainda mais profundo de significações, este tipo de narrativas permite que se entrevejam verdadeiras disputas de sentidos no interior dos valores cavaleirescos. A noção de "fidelidade", por exemplo, é definida e redefinida de diversas maneiras, dando voz a múltiplas visões de mundo. Registre-se ainda que, embora sejam comuns as narrativas de traições premeditadas de ordens diversas, a transgressão pode se dar por incompetência cavaleiresca. É o caso da narrativa "Gonçalo Pires Ribeiro" (LL 41L5-6). Encarregado por contrato vassálico de defender e administrar dois castelos, o nobre os entrega a dois vilões - portanto personagens situados fora do âmbito cavaleiresco. A perda dos castelos por esses personagens torna-se culpa do próprio nobre, que lhes delegara, indevidamente, essa função, que normalmente deveria caber, por competência e direito, a cavaleiros nobres. A narrativa é taxativa ao registrar a estagnação de Gonçalo Pires Ribeiro no âmbito não-cavaleiresco: "E assi ficou Gonçalo Pirez Ribeiro en tal pena e tal desventura qual ouvides" (Livro de linhagens do Conde Dom Pedro, 1980). Acrescentando logo em seguida que o nobre não deixou descendência, o genealogista acrescenta que "nom houverom semel, e julgou-lhe Deus bem" (Livro de linhagens do Conde Dom Pedro, 1980).

As narrativas sobre traidores correspondem aos que, como dissemos, partem de um equilíbrio inicial no campo cavaleiresco e, fazendo o seu trajeto coincidir com o percurso da transgressão, lá permanecem. Frequentemente, essas narrativas costumam registrar a estagnação das personagens no campo não-cavaleiresco, encerrando-se com frases do tipo: "e ficou por traidor". Em termos da forma como se dá a trajetória da transgressão pelo traidor, a passagem (de "a" para "b") pode ser consciente (calculada) ou inconsciente (a princípio imprevista pelo seu praticante). No primeiro caso - o da transgressão consciente - há uma clara diferença do traidor em relação ao "bom nobre" que transgride os valores cavaleirescos, também conscientemente, mas com vistas a uma finalidade maior. A motivação do traidor 
é sempre a satisfação de um interesse pessoal, uma ambição, uma covardia. É um recurso recorrente disforizar a figura do traidor ou a sua trajetória acrescentando-lhes outros índices de transgressão cavaleiresca, que não o tema principal da narrativa. Assim, além da traição maior que constitui a sequência principal, é comum aqui o registro de uma série de pequenos atos não-cavaleirescos que compõem o "perfil traidor" do personagem depreciado ${ }^{11}$.

Pode se dar, enfim, que o traidor seja levado, inconscientemente ou contra a sua vontade, ao âmbito da transgressão cavaleiresca, mas lá permaneça, sem força ou qualidades morais que o permitam iniciar o trajeto de volta. Nos relatos sobre "O rei Ramiro em Gaia”, o percurso de uma personagem feminina é exatamente deste tipo. Raptada por um mouro, a rainha Aldora, esposa do rei Ramiro, acaba apreciando mais a nova vida que a anterior, o que equivale a uma dupla traição, ao mesmo tempo voltada contra os preceitos cavaleirescos e contra a inclusão na cristandade. A narrativa também pode ser abordada, por outro lado, em termos de transgressão cristã ${ }^{12}$. Ao final da narrativa, a rainha é trazida à força de volta ao âmbito da normalidade, mas recusando este caminho de volta acaba condenada à morte, o que sela a sua estagnação no âmbito não-cavaleiresco. Essa situação corresponde à metade do circuito completo que vimos para o caso da narrativa sobre Pedro Alvelo. A diferença é, precisamente, a ausência do retorno pelo percurso de volta, obrigatório para o caso do bom nobre que não tenha perdido a sua essência.

\section{Os resgates narrativos do herói}

Um episódio de transgressão cavaleiresca pode ainda ser enxertado, às vezes em forma de sequência interpolada, no enredo mais amplo da narrativa, produzindo, com isso, ambiguidades com relação à atuação honrada do personagem cavaleiresco no decorrer da aventura. O herói, que no plano geral da narrativa tem um saldo cavaleiresco positivo, pode, em alguns casos, carregar um pequeno insucesso anticavaleiresco que é devidamente punido pelo destino, deixando-lhe sequelas que servirão de exemplo moral. É o exemplo do famoso relato sobre a luta de Afonso Henriques contra sua mãe, em que este a prende a ferros e é por isso amaldiçoado, vindo a sofrer, mais tarde, uma punição que se expressa

11 As narrativas das traições de "Portocarreiro" (LL 43F5) e "Mem Cravo" (LL 47C4) são ricas nestes aspectos. Ambas contêm referências a raptos. A primeira acrescenta ainda o desrespeito injustificado pelas insígnias régias e o expediente sorrateiro de invadir a casa do rei durante a noite para lhe roubar a mulher.

12 [Trajeto proposto: (S1) "Justiça" (a rainha é esposa do rei) $\rightarrow$ (-S1) "Não-justiça” (a esposa é levada pelo mouro contra a sua vontade) $\rightarrow$ (S2) "Injustiça" (a vítima adere ao seu raptor)]. 
através da perna quebrada (LL 7B1-10). O enxerto se presta, naturalmente, a mostrar que mesmo o rei está sujeito a um código mais amplo que não pode ser transgredido. Heroico e cavaleiresco no plano superior da narrativa, o rei fracassa em um pequeno detalhe e recebe, por isso, uma punição correspondente, que não chega a comprometer, em todo o caso, a sua história de vida, conforme a leitura do nobiliário. De maneira similar, na narrativa "O rei Ramiro em Gaia" (LL 21A1) o filho do rei amaldiçoa a mãe e sofre, por isso, uma punição correspondente: "E por este pecado que disse o infante dom Ordonho contra sa madre, disserom despois as gentes que por esso fora deserdado dos poboos de Castela ..." (Livro de linhagens do Conde Dom Pedro, 1980). ${ }^{13}$

Registram-se também, nos livros de linhagens, as narrativas que se resolvem no próprio âmbito cavalheiresco, confrontando, por exemplo, dois nobres honrados, mas que são opositores por algum motivo ${ }^{14}$. Nos antípodas do tipo de narrativa, que se resolve toda no próprio âmbito cavaleiresco, estão naturalmente as narrativas que se resolvem integralmente no âmbito não-cavaleiresco. Um exemplo significativo, e carregado de ambiguidades, é a narrativa sobre "Soeiro Pais Mouro e Urraca Mendes de Bragança”. Uma mulher da família dos Braganções pratica, desde o princípio da narrativa, o adultério com um nobre que tem o agravante de possuir uma ascendência materna moura (pode ser identificado a um filho bastardo de Soeiro Mendes da Maia). Enquanto isso, o marido participa honrosamente de uma campanha de Afonso Henriques contra os mouros, vindo, a certa altura, a morrer no campo de batalha. Informada da morte do marido, a mulher "nom leixou porem de casar com dom Soeiro Mouro" (Livro de linhagens do Conde Dom Pedro, 1980). O jogo entre legitimação e ilegitimação é particularmente ambíguo nesta narrativa que envolve depreciações várias aos diversos personagens envolvidos. Tudo permanece, naturalmente, no âmbito não-cavaleiresco - e a menção à atuação honrosa e cavaleiresca do marido na guerra apenas contribui para realçar a transgressão da esposa adúltera, da mesma forma que se insinua que a legitimação trazida pelo novo casamento apenas oficializa uma relação adúltera na sua origem (já a LV 6G5 apresenta uma versão não-agressiva desta união).

E há ainda as que começam de maneira invertida, fazendo a passagem do nãocavaleiresco ao cavaleiresco. A narrativa sobre "A Independência de Biscaia" (LL 9A1) mostra-nos uma sociedade oprimida por um cavaleiro injusto e cruel. A

13 [Trajeto proposto: (S1) "Normalidade cavaleiresca" $\rightarrow(-\mathrm{S} 1)$ "Não normalidade cavaleiresca" $\rightarrow$ (S2) "infração não-cavaleiresca" $\rightarrow$ (-S2)"punição da infração não cavaleiresca" $\rightarrow$ (S1) restabelecimento de uma nova normalidade cavalheiresca].

14 Entre as deste tipo, a narrativa sobre o "Conde Froia Bermudes" concilia um nobre honrado e cortês com o rei, que também permanece o tempo todo no âmbito cavalheiresco. (LL 7A5-7). 
normalização da situação não-cavaleiresca só ocorre quando um novo cavaleiro oferece-se como senhor para os habitantes da região e derrota o cavaleiro opressor, restabelecendo a justiça e a ordem. A possibilidade de enquadramento no quadrado semiótico proposto é clara: não apenas o novo cavaleiro não pratica os atos injustos do cavaleiro opressor (cobrança extorsiva de rendas), como ainda pratica atos justos e cavalheirescos, passando a defender dedicadamente a sociedade local contra futuros abusos.

Uma ética de fundo aristotélico, enfim, atravessa todo o conjunto de narrativas incluídas nos livros de linhagens medievais portugueses. E para um estudo mais sistemático, remetemos ao trabalho já realizado, que, embora não tendo tematizado mais diretamente a questão da intertextualidade aristotélica nos livros de linhagens, abriu, certamente, essas possibilidades, apresentando-as como promissor campo para estudos futuros.

\begin{abstract}
In this article, due to the concern in examining the intertextuality of Medieval Literature with the Aristotelian thought, we will examine some medieval narratives from the Portuguese Middle Age, present in the linage books from the $13^{\text {th }}$ century. The aim is to identify the main aspects of a Knight's Imaginary, which was essential for the formation of the aristocratic identity of the period. In this sense, we will investigate the influence of the Aristotelian ethics in the knight's pattern that is preponderantly defined in the genealogic narratives.
\end{abstract}

Keywords: Aristotelian ethics. Medieval narratives. Iberian Middle Age.

\title{
Referências
}

ARISTÓTELES. Ética a Nicômaco. São Paulo: Abril Cultural, 1973. v. IV. (Coleção Os Pensadores).

BARROS, José. As três imagens do rei - o imaginário régio nos livros de linhagens e nas cantigas trovadorescas portuguesas (séculos XIII-XIV), Tese (Doutorado). Niterói: UFF,1999.

BONI, Luis A. de. Apresentação. In: São Tomás de Aquino. Suma teológica. Porto Alegre: UFRS, 1980. p. I-XVII. 
CHEVALIER, Jacques. Histoire de la pensée. Paris: Racine, 1956. v. II.

GAUTHIER, René-Antoine. La morale d'Aristote. Paris: Presses Universitaires de France, 1958.

GILSON, Etienne. A filosofia na Idade Média. São Paulo: Martins Fontes, 1998. HÖFFE, Otfried. Aristóteles. Porto Alegre: Artmed, 2008.

Livro de Linhagens do Conde Dom Pedro. ed. José Mattoso. Nova Série dos Portugaliae Monumenta Historica. Lisboa: A.C.L., 1980.

MATOS, Manuel Cadafaz de. Contributo para o estudo da recepção dos textos de Averróis (1126-1198) na península ibérica entre os séculos XIII e XV numa perspectiva da História do Livro. Coimbra: Humanitas, 1998. vol.L, p. 441-ss.

NODARI, Paulo Cesar. A ética aristotélica. Síntese Nova Fase. Belo Horizonte:UFMG, v. 24, n. 79, 1997. p. 383-410.

URVOY. Dominique. Averroès: Les ambitions d'un intellectuel musulman. Paris: Flammarion, 1998.

Submetido em: 02 de julho de 2014. Aceito para publicação em: 09 de outubro de 2015. 